\title{
UNBS5162 inhibits proliferation of human melanoma cells by inducing apoptosis via the PI3K/Akt pathway
}

\author{
XUELI SHI ${ }^{1}$, LIU YANG $^{2}$, JUN XIE $^{3}$, YUMEI ZHAO ${ }^{1}$, JUNZI CONG $^{1}$, \\ ZHIPING LI ${ }^{1}$, HAIYAN LI ${ }^{1}$, XIANZHI CHENG ${ }^{1}$ and JINGHUI FAN ${ }^{1}$ \\ Departments of ${ }^{1}$ Pharmacy, ${ }^{2}$ Central Sterile Supply and ${ }^{3}$ Nephrology, \\ Hongqi Hospital Affiliated to Mudanjiang Medical University, Mudanjiang, Heilongjiang 157011, P.R. China
}

Received October 13, 2017; Accepted April 13, 2018

DOI: $10.3892 / \mathrm{mmr} .2018 .9321$

\begin{abstract}
UNBS5162, a novel naphthalimide, is generated by UNBS3157 hydrolysis in physiological saline. In the present study, the effects of UNBS5162 on M14 human melanoma cells were evaluated by Cell Counting Kit- 8 and transwell assays, as well as western blotting. The underlying mechanism of apoptosis induced by UNBS5162 was investigated. The results demonstrated that proliferation of UNBS5162-treated M14 melanoma cells was markedly inhibited in a time-dependent manner. The flow cytometry results indicated a markedly increased apoptosis rate in the experimental group compared with in the control group ( $23.8 \pm 0.4$ vs. $7.62 \pm 0.5 \%)$. Microscopy analysis revealed that the invasive and migratory abilities of UNBS5162-treated M14 cells were markedly suppressed. Furthermore, UNBS5162 treatment led to decreased expression of the anti-apoptotic protein B-cell lymphoma 2, but increased expression of the pro-apoptotic proteins Bcl-2-associated X protein and caspase-3. In addition, the expression of several key proteins involved in the phosphatidylinositol-4,5-bisphosphate 3-kinase/protein kinase $\mathrm{B} / \mathrm{mammalian}$ target of rapamycin (PI3K/Akt/mTOR) signaling pathway was altered in M14 cells treated with UNBS5162. Based on these results, it may be hypothesized that UNBS5162 suppresses the proliferation of M14 cells by inducing apoptosis via inhibition of key proteins in the $\mathrm{PI} 3 \mathrm{~K} / \mathrm{Akt} / \mathrm{mTOR}$ signaling pathway.
\end{abstract}

\section{Introduction}

Melanoma is a malignant tumor caused by excessive proliferation of abnormal melanocytes and most commonly occurs in the skin, but also occurs in the mucosa and eye choroid. In addition, melanoma accounts for a large proportion of cases of

Correspondence to: Miss Jinghui Fan, Department of Pharmacy, Hongqi Hospital Affiliated to Mudanjiang Medical University, 5 Tongxiang Road, Mudanjiang, Heilongjiang 157011, P.R. China E-mail: fanjinghui_0314@163.com

Key words: melanoma, apoptosis, naphthalimides, signaling pathway skin tumour-associated mortality (1). There are several factors that can induce the onset of melanoma, including sunlight exposure, family history, occurrence of nevus, giant congenital melanocytic nevi and dysplastic nevi syndrome $(2,3)$. In addition, the morbidity of melanoma varies with race and geographical region; for example, the incidence in Caucasians is much higher compared with in people of African descent. Although the survival rate for patients with melanoma has been greatly improved due to advances in research and treatment, the overall morbidity of melanoma is still increasing with an annual increase of 3 to 5\% (4,5). Since melanoma cells possess a high degree of malignancy, rapid growth rate and early metastatic characteristics, finding effective treatments to suppress proliferation of these cells is particularly important.

Naphthalimides, a class of compounds that binds DNA by intercalation, are known as potential anti-cancer agents (6). Numerous clinical trials have been performed using naphthalimides, including mitonafide, DMP840, amonafide and elinafide (7). However, dose-limiting bone marrow toxicity, leading to thrombocytopenia, anaemia and leukopenia, has meant that naphthalimides in general and amonafide in particular have failed to pass Phase III clinical trials (8). Amonafide is metabolized by $\mathrm{N}$-acetyl transferase- 2 to form $\mathrm{N}$-acetyl amonafide, which is a toxic metabolite $(9,10)$. To prevent toxicity and improve therapeutic outcome, a class of bis-intercalating agents were derived from naphthalimides (11). UNBS3157, a naphthalimide derivative, was designed to overcome the metabolism that induces the clinical haematotoxicity of amonafide. Several studies have reported that UNBS3157 possesses a three- to four-fold higher maximum tolerated dose regardless of route of administration and does not induce blood toxicity at therapeutic doses (12-14).

UNBS5162, N-\{2-[2-(dimethylamino)ethyl]-1,3-dioxo2,3-dihydro-1H-benzo[de] isoquinolin-5-yl\}urea, is a novel naphthalimide derivative that can be generated by UNBS3157 hydrolysis in physiological saline (15). The anti-cancer activity of UNBS5162 was investigated by Mijatovic et al (16) using experimental models of refractory human prostate cancer and the results revealed that expression of proangiogenic $(\mathrm{C}-\mathrm{X}-\mathrm{C}$ motif) ligand (CXCL) chemokines was almost completely eliminated following UNBS5162 treatment. However, the anti-tumor effects of UNBS5162 in other diseases remain unknown. The aim of the present study was to investigate the 
effects of UNBS5162 on melanoma and its overall mechanism of action.

\section{Materials and methods}

Cell culture. The M14 human melanoma cell line was obtained from the Cell Bank of the Chinese Academy of Sciences (Shanghai, China). Cells were maintained in RPMI-1640 (Gibco; Thermo Fisher Scientific, Inc., Waltham, MA, USA) supplemented with $100 \mathrm{U} / \mathrm{ml}$ penicillin, $0.1 \mathrm{mg} / \mathrm{ml}$ streptomycin (Sigma-Aldrich; Merck KGaA, Darmstadt, Germany) and 10\% fetal bovine serum (Invitrogen; Thermo Fisher Scientific, Inc.). Cells were cultured in a humidified atmosphere containing 5\% $\mathrm{CO}_{2}$. Once cell confluence reached $\sim 80 \%$, they were treated with $10 \mu \mathrm{M}$ UNBS5162 (MedChemExpress, Princeton, NJ, USA) or $0.1 \%$ dimethyl sulfoxide (DMSO, Amresco, LLC, Solon, OH, USA) for $24 \mathrm{~h}$ at room temperature. DMSO-treated cells were used as the negative control (NC) group.

Western blotting. Total protein was extracted from UNBS5162and DMSO-treated cells using radioimmunoprecipitation assay buffer (Beijing ComWin Biotech Co., Ltd., Beijing, China), followed by centrifugation at $12,000 \mathrm{x} \mathrm{g}$ and $4^{\circ} \mathrm{C}$ for $10 \mathrm{~min}$. Protein concentration was determined using bicinchoninic acid assay and equal amounts of proteins $(20 \mu \mathrm{g} /$ lane $)$ were separated by $8-15 \%$ SDS-PAGE. Following electrophoresis, the proteins on the gel were transferred onto polyvinylidene difluoride membranes. Membranes were blocked with 5\% bovine serum albumin (Gibco; Thermo Fisher Scientific, Inc.) for $1 \mathrm{~h}$ at room temperature and incubated overnight at $4^{\circ} \mathrm{C}$ with appropriate primary antibodies purchased from Wuhan Sanying Biotechnology (Wuhan, China), including rabbit anti-human Akt (cat. no. 60203-2-Ig; 1:1,000), phosphorylated (p)-Akt (cat. no. 66444-1-Ig; 1:1,000), mTOR (cat. no. 20657-1-AP; 1:1,000), p-mTOR (cat. no. 20984-1-AP; 1:1,000), rabbit anti-human ribosomal protein $\mathrm{S} 6$ kinase (p70S6K; cat. no. 66638-1-Ig; 1:1,000), B-cell lymphoma 2 (cat. no. 60178-1-Ig; Bcl-2; 1:1,000), Bcl-2-associated X protein (Bax; cat. no. 60267-1-Ig; 1:1,000), active caspase-3 (cat. no. 66470-2-Ig; 1:1,000) and GAPDH (cat. no. 60004-1-Ig; 1:5,000). The membranes were subsequently washed using Tris-buffered saline with $0.1 \%$ Tween-20 and incubated with goat anti-mouse horseradish peroxidase (HRP)-conjugated igG secondary antibodies (cat. no. SA00001-1; 1:5,000; Wuhan Sanying Biotechnology, Wuhan, China) or goat anti-rabbit HRP-conjugated IgG secondary antibodies (cat. no. SA00001-2; 1:5,000; Wuhan Sanying Biotechnology) at room temperature for $1 \mathrm{~h}$. Finally, the immunoreactive bands were visualized by the ECL ${ }^{\text {TM }}$ Prime Western Blotting system (APG Bio Ltd., Shanghai, China). Semi-quantitative analysis was conducted using Quantity-One software 4.0 (Bio-Rad Laboratories, Inc., Hercules, CA, USA) to measure densitometric values for each band, with GAPDH selected as the internal control. The relative protein expression between target protein and internal control was calculated.

Cell proliferation assay. Cell proliferation was measured using a Cell Counting Kit-8 (CCK-8; Dojindo Molecular Technologies, Inc., Kumamoto, Japan) assay. M14 cells were seeded into 96-well plates at 1,000 cells/well and treated with
$10 \mu \mathrm{M}$ UNBS5162 or $0.1 \%$ DMSO for $1.5 \mathrm{~h}$ at $37^{\circ} \mathrm{C}$. CCK-8 reagent was added every $24 \mathrm{~h}$ and incubated for $1.5 \mathrm{~h}$ at $37^{\circ} \mathrm{C}$. The optical density (OD) values of each well were measured by a microplate reader set at $450 \mathrm{~nm}$.

Transwell migration and invasion assays. A total of $100 \mu \mathrm{l}$ Matrigel (diluted 1:6 in serum-free medium) was added to evenly cover 24 -well transwell inserts, and incubated at $37^{\circ} \mathrm{C}$ for 4-6 h until set. The transwell chamber was washed with serum-free medium. UNBS5162- or DMSO-treated cells $\left(1 \times 10^{5}, 100 \mu \mathrm{l}\right)$ were suspended in serum-free medium and added to the upper chambers. RPMI-1640 medium containing $10 \%$ fetal bovine serum $(500 \mu \mathrm{l})$ was added to the lower chambers, and the cells were incubated overnight at $37^{\circ} \mathrm{C}$. Residual cells in the upper chamber were removed with a cotton swab. Cells that passed through the Matrigel-coated membrane were fixed with $4 \%$ paraformaldehyde for $30 \mathrm{~min}$ and then stained with $0.1 \%$ crystal violet for $20 \mathrm{~min}$ at room temperature. Cell invasion was quantified using an inverted light microscope (magnification, x100; CKX41; Olympus Corporation, Tokyo, Japan) and by randomly selecting five regions for cell counting. The migration assay was conducted following the same protocol as the invasion assay, but without application of Matrigel. A total of 5,000 cells were added to the upper chambers.

Detecting cell apoptosis by flow cytometry. After $24 \mathrm{~h}$ of UNBS5162 or DMSO treatment, cells were cultured in serum-free medium for $24 \mathrm{~h}$ at $37^{\circ} \mathrm{C}$. Subsequently, cells were dissociated using a trypsin solution without EDTA and centrifuged at 2,500 x g for $5 \mathrm{~min}$ at $4^{\circ} \mathrm{C}$. Cells were resuspended in $100 \mu \mathrm{l}$ Annexin V-fluorescein isothiocyanate (FITC) and propidium iodide (PI) solution (BestBio, Shanghai, China), and incubated at $25^{\circ} \mathrm{C}$ in the dark for $15 \mathrm{~min}$. After staining, the incubation buffer was removed by centrifugation at $2,500 \mathrm{xg}$ for $5 \mathrm{~min}$ at $4^{\circ} \mathrm{C}$ and cells were further cultured at $4^{\circ} \mathrm{C}$ for $20 \mathrm{~min}$ in the dark with occasional agitation. Flow cytometry was conducted with an excitation wavelength of $488 \mathrm{~nm}$ and the data were analyzed using a FlowJo software 7.2 (Tree Star, Inc., Ashland, OR, USA). In the bivariate scatter plots, necrotic, advanced apoptotic, early apoptotic and live cells are represented in the upper left (Q1), upper right (Q2), lower right (Q3) and lower left (Q4) quadrants, respectively.

Statistical analysis. SPSS 18.0 statistical analysis software (SPSS, Inc., Chicago, IL, USA) was used to analyze the experimental data. All data are expressed as the means \pm standard deviation of three independent experiments. The Student's t-test was used to compare data derived from two independent groups and $\mathrm{P}<0.05$ was considered to indicate a statistically significant difference.

\section{Results}

UNBS5162 inhibits proliferation of M14 cells. CCK-8 reagent was used to measure the effects of UNBS5162 on M14 cell proliferation, and the results of the CCK-8 proliferation assay are shown in Fig. 1. UNBS5162 treatment inhibited proliferation of M14 cells in a time-dependent manner. A statistically significant difference $(\mathrm{P}<0.05)$ in proliferation between the 


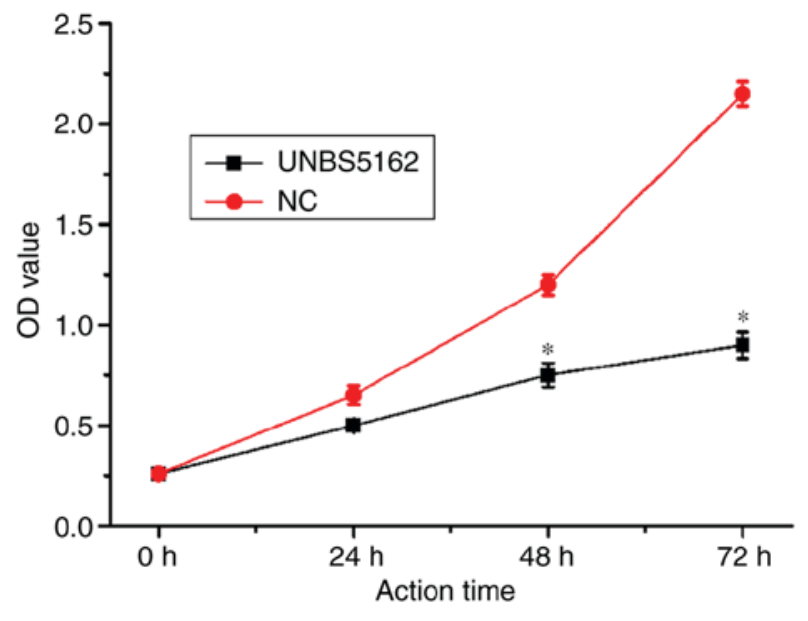

Figure 1. Effects of UNBS5162 on proliferation of human melanoma cells Cell Counting Kit- 8 cell proliferation assays were performed on M14 cells treated with UNBS5162 for 24,48 and $72 \mathrm{~h}$. ${ }^{*} \mathrm{P}<0.05$ vs. the NC group. NC, negative control; OD, optical density.

UNBS5162- and DMSO-treated groups was observed at 48 and $72 \mathrm{~h}$ post-treatment. These results suggested that proliferation of M14 cells may be markedly decreased following prolonged exposure to UNBS5162.

UNBS5162 induces apoptosis of M14 melanoma cells. To investigate whether UNBS5162 causes cell death via apoptosis, Annexin V-FITC/PI staining and flow cytometric analysis were performed. Q2 and Q3 were used to compare the apoptotic rate of M14 cells in the experimental and control group. As shown in Fig. 2A, the apoptotic rate in the Q2 and Q3 quadrants of the NC group was $~ 4$ and 3\%, whereas a higher apoptotic rate of $\sim 13$ and $11 \%$ was observed for cells treated with UNBS5162. These findings demonstrated that total apoptotic rate of UNBS5162-treated cells was increased $(23.8 \pm 0.4 \%)$ compared with DMSO-treated cells $(7.62 \pm 0.5 \%)$. In addition, western blotting was utilized to analyse the effects of UNBS5162 on expression of melanoma-associated apoptosis regulators in M14 cells. Western blot analysis of apoptosis regulators following UNBS5162 and DMSO treatment is shown in Fig. 2B. The results revealed a decrease in the expression levels of the anti-apoptotic protein B-cell lymphoma 2 (Bcl-2) and an increase in the expression of proapoptotic proteins, Caspase-3 and Bcl-2-associated X protein (Bax). The expression levels of apoptosis-associated proteins relative to GAPDH are shown in Fig. 2C. Compared with in the $\mathrm{NC}$ group, expression of the anti-apoptotic protein Bcl-2 was significantly downregulated, whereas proapoptotic proteins Caspase-3 and Bax were significantly upregulated in the experimental group.

UNBS5162 inhibits migration and invasion of M14 cells. The migration and invasion of UNBS5162- and DMSO-treated cells were observed by microscopy, and the results are shown in Fig. 3. The number of cells counted in five random fields per chamber was reduced in the experimental group compared with in the NC group (Fig. 3A), indicating that the number of migrated ( $25 \pm 6$ vs. $57 \pm 3$ cells) and invasive $(62 \pm 2$ vs. $120 \pm 5$ cells) M14 cells was significantly reduced following
UNBS5162 treatment ( $\mathrm{P}<0.05$; Fig. 3B). Conversely, a large number of cells treated with DMSO was observed in both the migration and invasion assays, as shown in Fig. 3A and B. The results revealed that the invasion and migration of UNBS5162-treated M14 cells was inhibited.

UNBS5162 suppresses activation of the PI3K signaling pathway in M14 cells. The PI3K signaling pathway is considered to be an important signaling pathway in tumours, and the associated proteins Akt and mTOR have a key role in promoting proliferation and metastasis of tumour cells. In addition, p70S6K, a downstream molecule of the PI3K signaling pathway, has been associated with proliferation of M14 cells (17). Western blot analysis was used to evaluate the protein expression levels of Akt, mTOR and p70S6K in M14 cells following UNBS5162 treatment, and the results are shown in Fig. $4 \mathrm{~A}$ and $\mathrm{B}$. The results revealed a significant downregulation of phosphorylated (p)-Akt and p-mTOR. In addition, the expression levels of $\mathrm{p} 70 \mathrm{~S} 6 \mathrm{~K}$, a protein associated with cellular proliferation, were significantly downregulated in the experimental grouped compared with in the NC group. These results suggested that UNBS5162 treatment may suppress PI3K/Akt/mTOR signaling in M14 melanoma cells.

\section{Discussion}

The novel naphthalimide, UNBS5162, has been demonstrated to be a DNA-targeting compound that is synthesized by UNBS3157 hydrolysis in physiological saline. UNBS3157 was initially designed to avoid the metabolism that induces haematotoxicity of amonafide (12). It has previously been demonstrated that UNBS3157, a non-haematotoxic naphthalimide, possesses significant anti-cancer activity in vivo (13). Therefore, a better understanding of the efficacy and mechanism of action of UNBS5162, a UNBS3157 derivative, is required. Mijatovic et al (16) reported that repeated administration of UNBS5162 in vivo can markedly improve survival in orthotopic human prostate cancer models by reducing the expression of CXCL chemokines. However, research on the anti-cancer activity of UNBS5162 for other diseases is still lacking; therefore, the aim of this study was to investigate the effect of UNBS5162 on melanoma.

In the present study, a CCK- 8 assay was used to measure the proliferation of M14 cells treated with UNBS5162, and the results demonstrated that proliferation was significantly inhibited at 48 and $72 \mathrm{~h}$ post-UNBS5162 treatment compared with in the NC group. Furthermore, the results from the transwell assays revealed that the number of invasive and migrated M14 cells was reduced following UNBS5162 treatment, suggesting that UNBS5162 inhibits invasion and migration of M14 cells. Notably, the apoptotic rate of UNBS5162-treated cells was significantly increased, which may have led to reduced invasive and migratory ability. Similar inhibitory effects in human retinoblastoma cells have been previously reported (18).

It has been reported that certain intracellular proteins can regulate apoptosis, including Bcl-2, Bax and Caspase-3 $(19,20)$. Bcl-2, an anti-apoptotic factor, is closely associated with tumour occurrence and resistance (21). Bax, a member of the proapoptotic protein family, when overexpressed not only allows various cell types to undergo spontaneous apoptosis, 
A

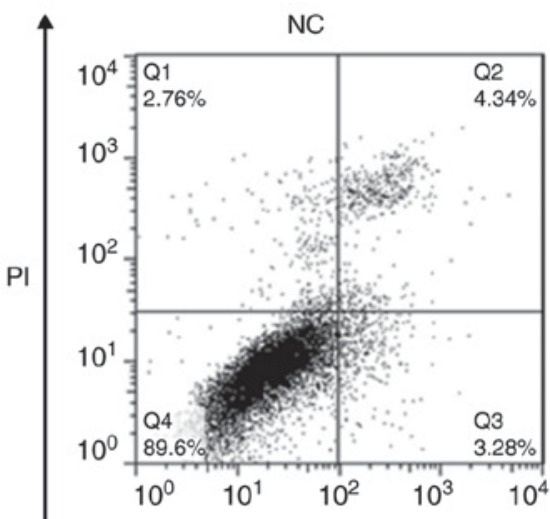

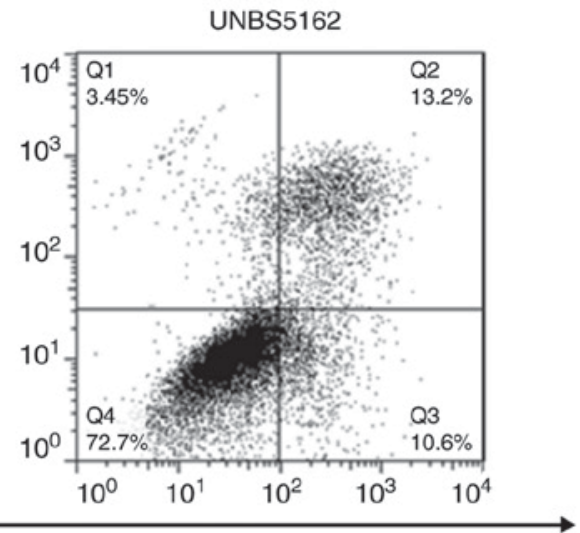

AnnexinV FITC

B
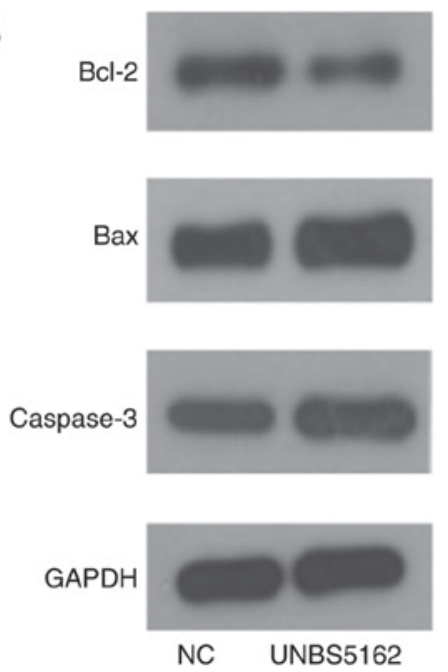
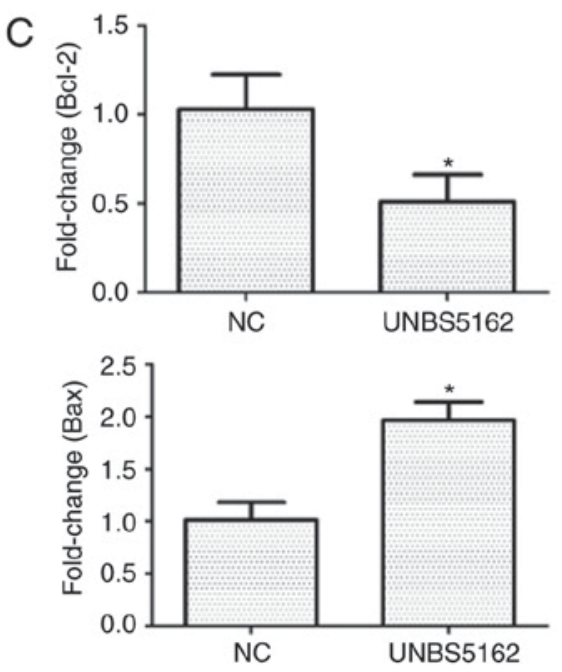
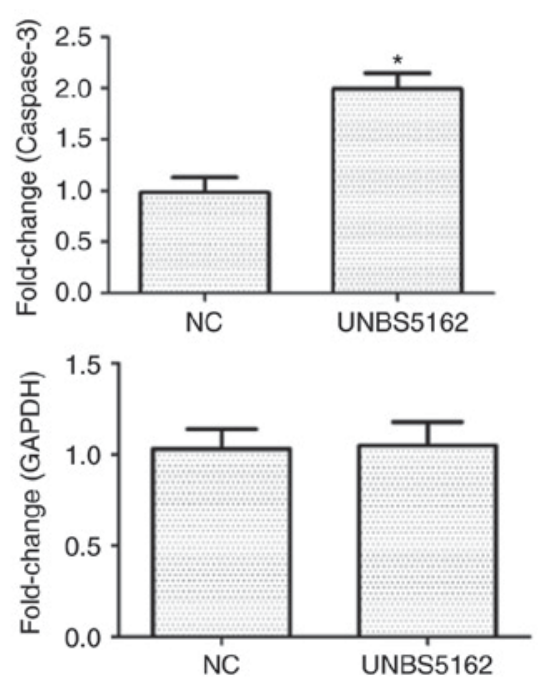

Figure 2. Detection of M14 cell apoptosis following UNBS5162 treatment. (A) Representative flow cytometry scatter plots of cells stained with Annexin V-FITC and PI. (B and C) Bcl-2, Bax and Caspase-3 protein expression levels in M14 cells were detected by western blotting. Results are representative of three independent experiments performed in triplicate. " $\mathrm{P}<0.05$ vs. the NC group. Bax, Bcl-2-associated X protein; Bcl-2, B-cell lymphoma 2; FITC, fluorescein isothiocyanate; $\mathrm{NC}$, negative control; PI, propidium iodide.

A

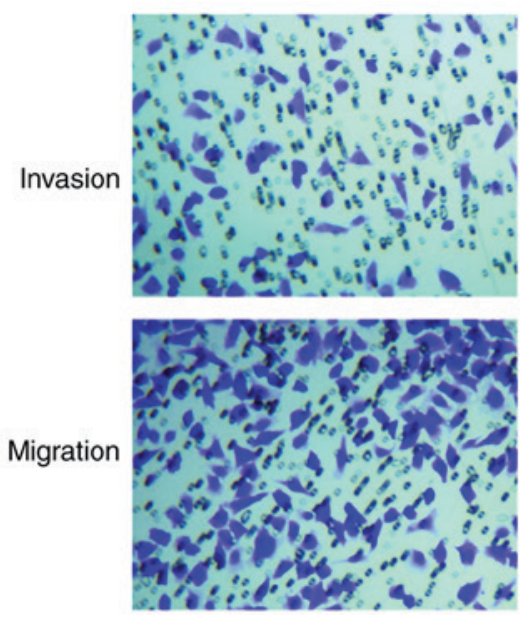

NC
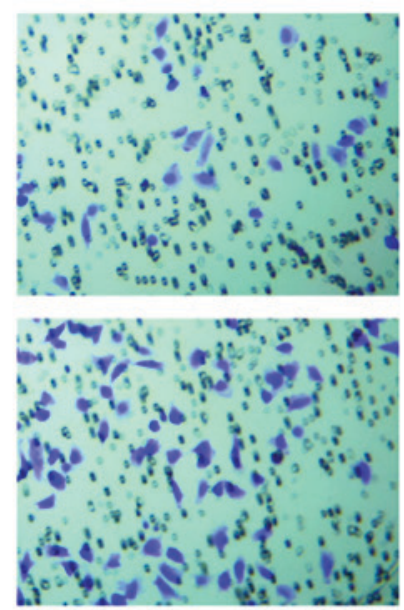

UNBS5162

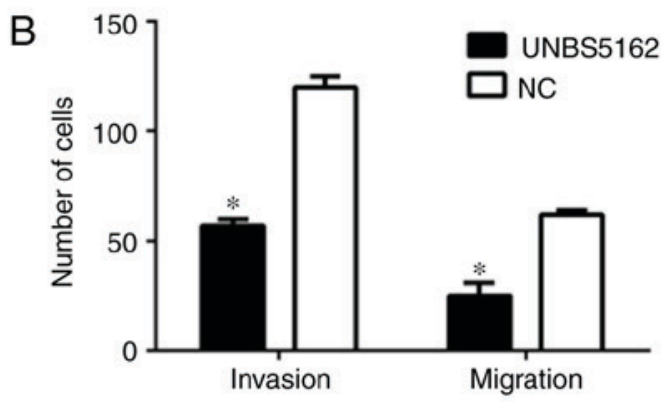

Figure 3. UNBS5162 inhibits M14 cell migration and invasion. (A) Migration and invasion of UNBS5162-treated M14 cells was determined using transwell migration and invasion assays, and visualized under a microscope. Magnification, x100. (B) The number of invasive and migrated cells was quantified. The average number of cells was quantified from three independent experiments. ${ }^{*} \mathrm{P}<0.05$ vs. the NC group. NC, negative control.

but also promotes apoptosis induced by other factors $(22,23)$.

Notably, the proteins Bcl-2 and Bax are antagonistic, and have a role in apoptosis via formation of a heterodimer $(24,25)$. Furthermore, Caspase-3 is required for Bax-induced apoptosis, 
A
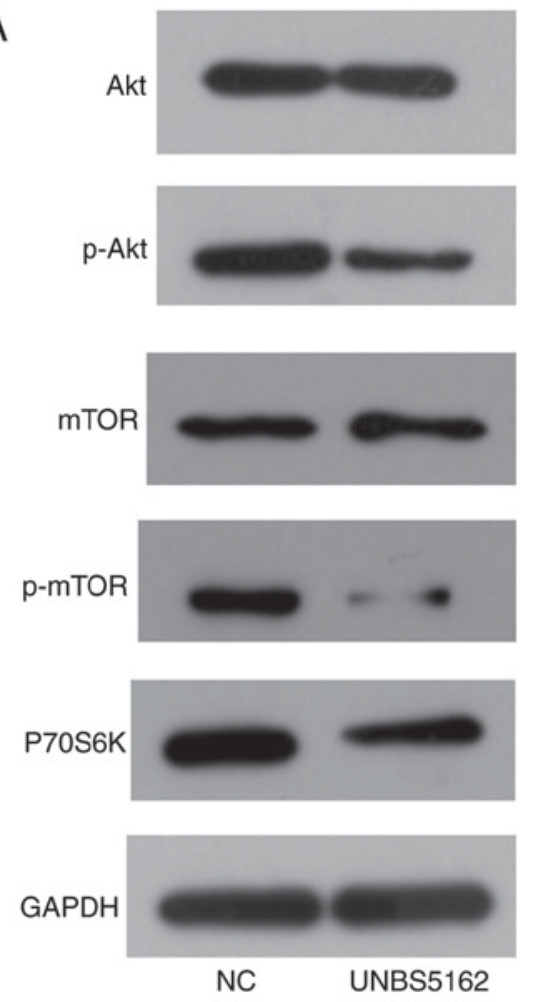

B
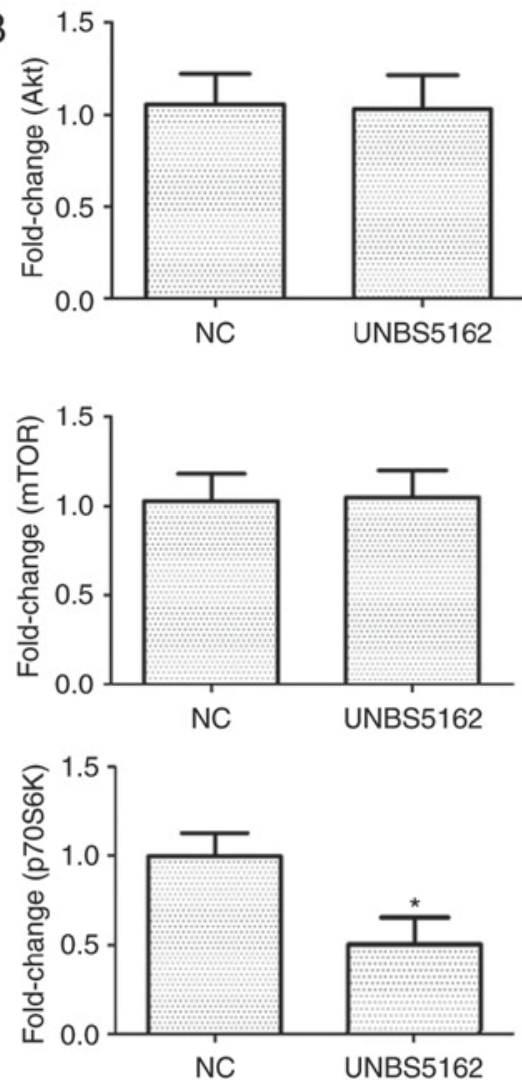
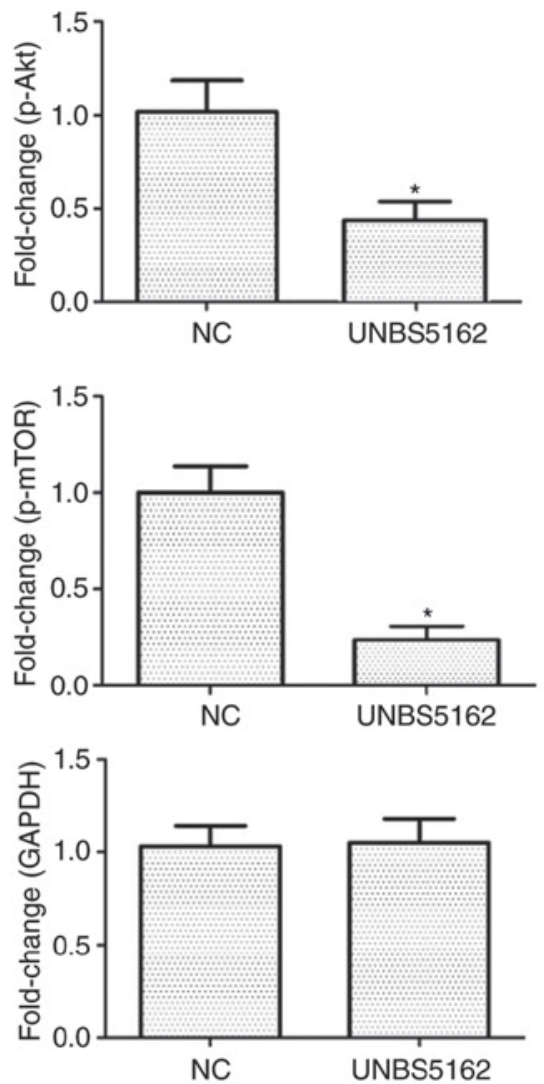

Figure 4. Activation of the PI3K/Akt signaling pathway is inhibited in UNBS5162-treated M14 cells. (A) Expression levels of Akt, p-Akt, mTOR, p-mTOR, p70S6K and internal control GAPDH in M14 cells were determined by western blot analysis. (B) Semi-quantitative analyses of protein expression levels are shown. Results are presented as the means \pm standard deviation from three independent experiments. * $\mathrm{P}<0.05$ vs. the NC group. Akt, protein kinase B; mTOR, mammalian target of rapamycin; NC, negative control; p70S6K, p70 ribosomal protein S6 kinase; p-, phosphorylated; PI3K, phosphatidylinositol-4, 5-bisphosphate 3-kinase.

and is located downstream of the Bcl-2 protein family. Therefore, activation of Caspase- 3 and its role in apoptosis is directly affected by the ratio of Bcl-2 and Bax expression (26). In the present study, the western blotting results demonstrated that expression of the anti-apoptotic protein $\mathrm{Bcl}-2$ was reduced in M14 cells treated with UNBS5162, whereas the proapoptotic protein Bax was highly expressed. In addition, Caspase-3 was highly expressed in UNBS5162-treated cells. These results suggested that UNBS5162 may contribute to enhancement of apoptosis in M14 cells.

The molecular mechanisms underlying the effects of UNBS5162 on proliferation and apoptosis were also investigated using M14 cells. Apoptosis is a programmed cell death process, which can be triggered by alterations in the intracellular and extracellular environment or by a death signal, and involves activation, expression and regulation of a series of genes. Activation of the PI3K/Akt/mTOR signaling pathway can inhibit stimulation-induced apoptosis and enhance cell cycle progression, and sequentially improve survival and increase proliferation of tumour cells $(27,28)$. PI3K in the PI3K/Akt/mTOR signaling pathway can increase activation of Akt by stimulating a signaling cascade that produces phosphatidylinositol triphosphate $(29,30)$. Akt is generally located at important intersections of multiple signaling pathways and can respond to various of intra- or extracellular stimuli by regulating survival signals $(31,32)$. Furthermore, the serine/threonine-protein kinase mTOR is a downstream effector of the PI3K/Akt signaling pathway, which acts as a key regulator of metastasis, invasion, survival and proliferation of tumour cells by activating p70S6K $(33,34)$. It has previously been suggested that the expression of $\mathrm{Bcl}-2$ and $\mathrm{Bax}$ proteins may be regulated by kinases and that their activation could be affected by mTOR (35).

In the present study, p-Akt and p-mTOR expression was downregulated following treatment of M14 cells with UNBS5162. Similarly, the expression levels of p70S6K, a downstream molecule in the PI3K/Akt/mTOR signaling pathway, were significantly reduced in the experimental group compared with in the NC group. Downregulation of proteins in the $\mathrm{PI} 3 \mathrm{~K} / \mathrm{Akt} / \mathrm{mTOR}$ signaling pathway indicated that UNBS5162 treatment may inhibit PI3K/Akt/mTOR signaling in M14 melanoma cells. Additionally, the migratory and invasive abilities of UNBS5162-treated cells were significantly suppressed. Wang et al (18) reported that the functional roles of UNBS5162 in human retinoblastoma cells may be regulated by the activity of the Akt-mTOR pathway in vitro. Additionally, the preclinical development of UNBS5162 in prostate cancer has been studied by Mahieu et al (15); the results indicated that UNBS5162 has anti-cancer effects in prostate cancer. Therefore, UNBS5162 may be a potential therapeutic agent for melanoma.

In conclusion, the results of the present study demonstrated that UNBS5162 significantly inhibits proliferation, invasion and migration of M14 cells. In addition, it may be hypothesized that UNBS5162 induces apoptosis through regulation of the PI3K/Akt/mTOR signaling pathway. 


\section{Acknowledgements}

Not applicable.

\section{Funding}

No funding was received.

\section{Availability of data and materials}

The datasets used and analyzed during the current study are available from the corresponding author on reasonable request.

\section{Authors' contributions}

XLS performed the experiments and analyzed the data, and was also a major contributor in writing the manuscript. LY, JX, YMZ and JZC made substantial contribution to the study conception and design. ZPL, HYL, XZC and JHF performed the statistical analysis. JHF was involved in the drafting of the manuscript and gave the final approval for publication. All authors read and approved the manuscript.

\section{Ethics approval and consent to participate}

Not applicable.

\section{Patient consent for publication}

Not applicable.

\section{Competing interests}

The authors declare that they have no competing interests.

\section{References}

1. Trinh VA: Current management of metastatic melanoma. Am J Health Syst Pharm 65 (Suppl 9): S3-S8, 2008.

2. Mete M, Sirakov NM, Griffin J and Menter A: A novel classification system for dysplastic nevus and malignant melanoma. In: Proceedings of the IEEE International Conference on Image Processing, Phoenix, AZ, pp3414-3418, 2016.

3. Cho E, Rosner BA and Colditz GA: Risk factors for melanoma by body site. Cancer Epidemiol Biomarkers Prev 14: 1241-1244, 2005.

4. Trautmann F, Meier F, Seidler A and Schmitt J: Effects of the German skin cancer screening programme on melanoma incidence and indicators of disease severity. Br J Dermatol 175: 912-919, 2016.

5. Whiteman DC, Green AC and Olsen CM: The Growing Burden of Invasive Melanoma: Projections of Incidence Rates and Numbers of New Cases in Six Susceptible Populations through 2031. J Invest Dermatol 136: 1161-1171, 2016.

6. Ingrassia L, Lefranc F, Kiss R and Mijatovic T: Naphthalimides and azonafides as promising anti-cancer agents. Curr Med Chem 16: 1192-1213, 2009.

7. Ralhan R and Kaur J: Alkylating agents and cancer therapy. Expert Opin Ther Pat 17: 1061-1075, 2007.

8. Xie L, Cui J, Qian X, Xu Y, Liu J and Xu R: 5-Non-amino aromatic substituted naphthalimides as potential antitumor agents: Synthesis via Suzuki reaction, antiproliferative activity, and DNA-binding behavior. Bioorg Med Chem 19: 961-967, 2011.

9. Zhu H, Huang M, Yang F, Chen Y, Miao ZH, Qian XH, Xu YF, Qin YX, Luo HB, Shen X, et al: R16, a novel amonafide analogue, induces apoptosis and G2-M arrest via poisoning topoisomerase II. Mol Cancer Ther 6: 484-495, 2007.
10. Antonini I, Volpini R, Dal Ben D, Lambertucci C and Cristalli G: Design, synthesis, and biological evaluation of new mitonafide derivatives as potential antitumor drugs. Bioorg Med Chem 16: 8440-8446, 2008.

11. Braña MF, Cacho M, García MA, de Pascual-Teresa B, Ramos A, Domínguez MT, Pozuelo JM, Abradelo C, Rey-Stolle MF, Yuste M, et al: New analogues of amonafide and elinafide, containing aromatic heterocycles: Synthesis, antitumor activity, molecular modeling, and DNA binding properties. J Med Chem 47: 1391-1399, 2004.

12. Dumont P, Ribaucour F, Quaquebeke EV, Darro F and Kiss R: UNBS3157, a new amonafide derivative with improved in vivo efficacy and decreased toxicity. Cancer Res 66: 1105, 2006.

13. Van Quaquebeke E, Mahieu T, Dumont P, Dewelle J, Ribaucour F, Simon G, Sauvage S, Gaussin JF, Tuti J, El Yazidi M, et al: 2,2,2-Trichloro-N-(\{2-[2-(dimethylamino) ethyl]-1,3-dioxo-2,3-dihydro-1H-benzo[de]isoquinolin-5-yl\} carbamoyl)acetamide (UNBS3157), a novel nonhematotoxic naphthalimide derivative with potent antitumor activity. J Med Chem 50: 4122-4134, 2007.

14. Seliga R, Pilatova M, Sarissky M, Viglasky V, Walko M and Mojzis J: Novel naphthalimide polyamine derivatives as potential antitumor agents. Mol Biol Rep 40: 4129-4137, 2013.

15. Mahieu T, Mijatovic T, Quaquebeke EV, Lefranc F, Vynckt FV, Darro F and Kiss R: UNBS5162 is a novel naphthalimide derivative that induces autophagy and senescence in human prostate cancer cells. Mol Cancer Ther 6: 3373S, 2007.

16. Mijatovic T, Mahieu T, Bruyère C, De Nève N, Dewelle J, Simon G, Dehoux MJM, van der Aar E, Haibe-Kains B, Bontempi G, et al: UNBS5162, a novel naphthalimide that decreases CXCL chemokine expression in experimental prostate cancers. Neoplasia 10: 573-586, 2008.

17. Babchia N, Calipel A, Mouriaux F, Faussat AM and Mascarelli F: The PI3K/Akt and mTOR/P70S6K signaling pathways in human uveal melanoma cells: Interaction with B-Raf/ERK. Invest Ophthalmol Vis Sci 51: 421-429, 2010.

18. Wang B, Shen J and Wang J: UNBS5162 inhibits proliferation of human retinoblastoma cells by promoting cell apoptosis. OncoTargets Ther 10: 5303-5309, 2017.

19. Kiliçkan L, Gonca S, Dalçik C, Dalçik H, Solak M, Bayindir O, Süzer K, Omay O and Calikan E: General anesthesia with thoracic epidural anesthesia in the cardiopulmonary bypass surgery reduces apoptosis by upregulating antiapoptotic protein Bcl-2. J Cardiovasc Surg (Torino) 47: 315-322, 2006.

20. Siddiqui WA, Ahad A and Ahsan H: The mystery of BCL2 family: Bcl-2 proteins and apoptosis: an update. Arch Toxicol 89: 289-317, 2015.

21. Wojtuszkiewicz A, Schuurhuis GJ, Kessler FL, Piersma SR, Knol JC, Pham TV, Jansen G, Musters RJ, van Meerloo J, Assaraf YG, et al: Exosomes Secreted by Apoptosis-Resistant Acute Myeloid Leukemia (AML) Blasts Harbor Regulatory Network Proteins Potentially Involved in Antagonism of Apoptosis. Mol Cell Proteomics 15: 1281-1298, 2016.

22. Huang L, Han J, Ben-Hail D, He L, Li B, Chen Z, Wang Y, Yang Y, Liu L, Zhu Y, et al: A New Fungal Diterpene Induces VDAC1-dependent Apoptosis in Bax/Bak-deficient Cells. J Biol Chem 290: 23563-23578, 2015.

23. Singh L, Pushker N, Saini N, Sen S, Sharma A, Bakhshi S, Chawla B and Kashyap S: Expression of pro-apoptotic Bax and anti-apoptotic Bcl-2 proteins in human retinoblastoma. Clin Experiment Ophthalmol 43: 259-267, 2015.

24. Zhu L, Han MB, Gao Y, Wang H, Dai L, Wen Y and Na LX: Curcumin triggers apoptosis via upregulation of $\mathrm{Bax} / \mathrm{Bcl}-2$ ratio and caspase activation in SW872 human adipocytes. Mol Med Rep 12: 1151-1156, 2015.

25. Zhou S, Wang Y and Zhu JJ: Simultaneous Detection of Tumor Cell Apoptosis Regulators Bcl-2 and Bax through a Dual-Signal-Marked Electrochemical Immunosensor. ACS Appl Mater Interfaces 8: 7674-7682, 2016.

26. Jiang H, Liu J, Gao J, Meng M, Qin X and Wang T: Up-regulations of Bax and caspase-3 and down-regulation of Bcl-2 after Xinfeng capsule treatment in adjuvant-induced arthritis rats. Xi Bao Yu Fen Zi Mian Yi Xue Za Zhi 32: 457-461, 2016 (In Chinese).

27. Wang D, Chen J, Chen H, Duan Z, Xu Q, Wei M, Wang L and Zhong M: Leptin regulates proliferation and apoptosis of colorectal carcinoma through PI3K/Akt/mTOR signalling pathway. J Biosci 37: 91-101, 2012.

28. Kang S, Dong SM, Kim BR, Park MS, Trink B, Byun HJ and Rho SB: Thioridazine induces apoptosis by targeting the $\mathrm{PI} 3 \mathrm{~K} / \mathrm{Akt} / \mathrm{mTOR}$ pathway in cervical and endometrial cancer cells. Apoptosis 17: 989-997, 2012. 
29. Sun $\mathrm{CH}$, Chang $\mathrm{YH}$ and Pan CC: Activation of the $\mathrm{PI} 3 \mathrm{~K} / \mathrm{Akt} / \mathrm{mTOR}$ pathway correlates with tumour progression and reduced survival in patients with urothelial carcinoma of the urinary bladder. Histopathology 58: 1054-1063, 2011.

30. Jiang Z, Liu Y and Wang C: Oncogenic NanogP8 expression regulates cell proliferation and migration through the Akt/mTOR signaling pathway in human gastric cancer - SGC-7901cell line. OncoTargets Ther 9: 4859-4866, 2016.

31. Leleu X, Coiteux V, Corm S, Robu D, Dupire S, Moreau AS, Gay J, Berthon C, Pascal L, Cliquenois E, et al: The AKT signaling pathway is the key regulator of cell survival and homing in Waldenstrom macroglobulinemia. Hématologie 14: 14-17, 2008.

32. Yang H, Zhou J, Mi J, Ma K, Fan Y, Ning J, Wang C, Wei X, Zhao $\mathrm{H}$ and Li E: HOXD10 acts as a tumor-suppressive factor via inhibition of the RHOC/AKT/MAPK pathway in human cholangiocellular carcinoma. Oncol Rep 34: 1681-1691, 2015.
33. Asnaghi L, Bruno P, Priulla M and Nicolin A: mTOR: A protein kinase switching between life and death. Pharmacol Res 50: 545-549, 2004

34. Yu JS and Cui W: Proliferation, survival and metabolism: The role of PI3K/AKT/mTOR signalling in pluripotency and cell fate determination. Development 143: 3050-3060, 2016.

35. Liu YD, Zheng QX, Wu HB, Guo XD, Li JF and Hao SF: The effects of rapamycin on expression ratio of $\mathrm{Bax} / \mathrm{Bcl}-2$ and the expression of activated caspase-3 in different types of tumor cells. Tumor 33: No. 2, 2013. 